\title{
Obesity in Gynecologic Oncology
}

\section{Adipositas in der gynäkologischen Onkologie}

(C) (1) $\Theta$

Authors

Heinz Kölbl, Thomas Bartl

\begin{abstract}
Affiliation
Klinische Abteilung für Allgemeine Gynäkologie und Gynäkologische Onkologie, Universitätsklinik für Frauenheilkunde, Medizinische Universität Wien, Wien, Austria
\end{abstract}

Key words

obesity, gynecological malignancies, BMI

Schlüsselwörter

Adipositas, gynäkologische Malignome, BMI

received

15.6. 2020

accepted after revision

25.7.2020

Bibliography

Geburtsh Frauenheilk 2020; 80: 1205-1211

DOI 10.1055/a-1124-7139

ISSN 0016-5751

(c) 2020. The Author(s).

This is an open access article published by Thieme under the terms of the Creative Commons Attribution-NonDerivative-NonCommercial-License, permitting copying and reproduction so long as the original work is given appropriate credit. Contents may not be used for commercial purposes, or adapted, remixed, transformed or built upon. (https://creativecommons.org/licenses/by-nc-nd/4.0/)

Georg Thieme Verlag KG, Rüdigerstraße 14,

70469 Stuttgart, Germany

Correspondence

Dr. med. Thomas Bartl

Klinische Abteilung für Allgemeine Gynäkologie und Gynä-

kologische Onkologie, Universitätsklinik für Frauenheilkunde,

Medizinische Universität Wien

Währinger Gürtel 18-20, 1090 Wien, Austria

thomas.bartl@meduniwien.ac.at

$\theta$

Deutsche Version unter:

https://doi.org/10.1055/a-1124-7139

\section{ABSTRACT}

The decades-long global obesity epidemic has resulted in steady increase in the incidence of obesity-related malignancies. The associated diagnostic and therapeutic implications present a clinical challenge for gynecologic oncology treatment strategies. Recent studies have provided solid evidence for an independent, linear, positive correlation between a pathologically increased body mass index and the probability of developing endometrial or postmenopausal breast cancer. The pathogenesis is complex and the subject of current research. Proposed causes include pathologically increased serum levels of sexual steroids and adiponectin, obesity-induced insulin resistance, and systemic inflammatory processes. The scientific evidence for an association between obesity and other gynecological malignancies is, however, less solid. The clinical relevance of obesity as a risk factor for epithelial ovarian cancer, cervical cancer and vulvar cancer appears to be negligible. Nevertheless, obesity appears to have a negative impact on prognosis and oncologic outcomes for all gynecological cancers. Whether or not this effect can be interpreted as correlative or causal is still a subject of ongoing debate.

\section{ZUSAMMENFASSUNG}

Als Folge der weltweit seit Jahrzehnten ansteigenden Adipositasprävalenz stellen die zunehmende Anzahl an Neudiagnosen adipositasassoziierter Malignome und damit einhergehende diagnostische und therapeutische Implikationen gynäkoonkologische Behandlungsstrategien vor eine Herausforderung. Im Spiegel der aktuellen Studienlage besteht solide Evidenz für eine unabhängige, linear positive Korrelation zwischen einem pathologisch erhöhten Body-Mass-Index und der Erkrankungswahrscheinlichkeit für Endometrium- und postmenopausale Mammakarzinome. Die Pathogenese ist komplex und Gegenstand intensiver Forschung, pathologisch erhöhte Serumspiegel von Sexualsteroiden und Adiponektinen, eine adipositasinduzierte Insulinresistenz sowie systemische Inflammationsprozesse werden als ursächlich diskutiert. Für andere gynäkologische Malignome zeigt sich die wissenschaftliche Evidenz weniger solide, Adipositas erscheint als Risikofaktor für epitheliale Ovarial,- Zervix und Vulvakarzinome von vergleichsweise untergeordneter klinischer Relevanz. Ein negativer Einfluss auf die Prognose und das onkologische Outcome zeigt sich hingegen für alle Tumorentitäten nachvollziehbar, wobei eine abschließende Bewertung, ob dieser Effekt korrelativ oder kausal zu interpretieren ist, weiterhin aussteht. 


\section{Introduction}

The global obesity rate has doubled in the years from 1980 to 2008 and continues to increase. In the European Union, depending on the region, between 10 and $30 \%$ of adults are classified as clinically obese, and in the USA up to $40 \%$ of adults meet the definition of pathologically obese, a rate which does not include moderate overweight $[1,2]$. Based on the 2016 WHO definition of a body mass index (BMI) of more than $30 \mathrm{~kg} / \mathrm{m}^{2}$, obesity is associated with serious long-term health sequelae which affect almost all organ systems. In recent decades, scientific research has begun to focus on the interaction between obesity and oncogenesis. Gynecological cancers occupy a key position, as postmenopausal breast cancer and endometrial cancer - both of which make up about $33 \%$ of all new cancer diagnoses in women in Austria per year - are the most common cancers associated with obesity [3]. It is estimated that around half of all cancers could be prevented based on our current level of research; around one third of all cancers in the western world are ascribed to poor nutrition and a lack of physical activity. In the words of the WHO at the start of the 2000s, the clinical implications of new diagnoses of potentially preventable cancers represents an "unheard-of health policy challenge" [4].

Despite the association between obesity and cancer incidence reported for decades and the increasing evidence of possibly causal pathophysiological connections, scientific investigations into the role of obesity in gynecologic oncology are far from complete. Not least because, apart from the reported association as an epidemiological risk factor for endometrial and postmenopausal breast cancer, the data is limited. As the currently available data largely consists of data from retrospective cohort studies, the question whether the reported association should be interpreted as causal or correlative cannot be conclusively answered [5].

Recently published research indicates that pathologically increased BMI may be a negative predictor for recurrence and disease-specific overall survival. Current research is focusing on the role of possible influencing factors such as increased perioperative complication rates and lower response rates to cytotoxic chemotherapy regimens. Recent data have also indicated possibly clinically relevant interactions between higher BMI and the response to immunotherapies.

Given the rise in cases with disease and the new scientific data, the well-known connection between obesity and gynecological cancers is becoming more significant. The aim of this article is to review the findings of current studies on the pathophysiology and epidemiology of obesity and their clinical implications for the treatment of gynecological cancers.

\section{Pathophysiological Background: Obesity and Oncogenesis}

The increase in fatty tissue due to obesity is associated with numerous pathological molecular changes which promote carcinogenesis and can have a negative impact on the course of disease in patients with gynecological cancers. In addition to the endocrine effects of the pathologically increased hormone production of adipocytes, obesity-induced insulin resistance and systemic inflammatory processes are also discussed as possible causes.

Obese fatty tissue is characterized by pathological infiltration of immunocompetent cells. While, physiologically, the majority of fatty tissue macrophages are anti-inflammatory M2 subtypes, there is an increase in both the relative and the absolute percentages of pro-inflammatory M1 macrophages in obese fatty tissue. Pathogenetically this could be interpreted as an immune response to cellular damage to the adipocytes caused by changes to cell membrane permeability by excessive absorption of saturated fatty acids [6]. Cytokines released by pro-inflammatory M1-type macrophages (including tumor necrosis factor- $\alpha$ [TNF- $\alpha$ ], interleukin-6 [IL-6] and interleukin-1 $\beta$ [IL-1B]) can have a direct oncogenic effect through activation of the NFKB and JNK signaling pathways and can cause oxidative DNA damage as a consequence of inflammatory processes, resulting in an increase in the cellular mutation load. Protective anti-inflammatory regulatory T-cells $\left(T_{\text {reg }}\right)$ disappear in obese fatty tissue, which additionally contributes to amplification of a pro-inflammatory spiral [7]. Inflammatory processes are not limited to fatty tissue; in obese patients they lead to a measurable increase in the serum levels of IL-6 and TNF- $\alpha$, which subsequently also manifest through elevated C-reactive protein (CRP) levels as markers of systemic inflammation $[8,9]$.

The second carcinogenic pathomechanism currently being discussed is obesity-induced insulin resistance. High insulin serum levels have been found to exert growth-stimulating and antiapoptotic effects in vitro and in vivo [10]. In the context of the chronic increase in lipolysis associated with obesity, elevated free fatty acid concentrations have been found to suppress insulin signaling pathways [11,12]. Physiologically, visceral fat has a higher lipolytic activity than peripheral fatty tissue, with predominantly upper-body fat distribution contributing further to the development of insulin resistance [13]. Elevated IL-6 and TNF $\alpha$ serum levels induced by obesity-related inflammatory processes are thought to lead to a synergistic increase in lipolytic activity [14]. Increased insulin sensitivity triggered by the somatic overexpression of insulin and fibroblast growth factor-1 (FGF1) receptors sensitizes cells to the pro-proliferative effects of insulin, contributing to the development of endometrial hyperplasia [15].

The possible carcinogenic effect of the peptide hormones adiponectin and leptin secreted by adipocytes is also being investigated. Adiponectin increases cellular insulin sensitivity and has an anti-inflammatory effect, with physiological adiponectin concentrations having an oncoprotective effect. Endocrine dysregulation may therefore facilitate carcinogenesis $[16,17]$. Leptin plays a key role in satiety regulation by the hypothalamus. Obesity is associated with leptin overexpression, with hypothalamic leptin resistance also leading to pathologically elevated concentrations. Leptin also stimulates angiogenesis processes and is likely to have a direct carcinogenic effect through the SAT3 signaling pathway. It has also been suggested that leptin may increase estrogen levels $[10,18]$.

Obese fatty tissue is associated with pathologically elevated estrogen levels as a consequence of the increased aromatase expression by adipocytes and the resulting increase in the aromatization of androstenedione and testosterone. By binding to estro- 
gen receptors $\alpha$ or $\beta$, estrogen initiates the transcription of proproliferative genes, which act as a growth signal for receptor-expressing gynecological cancers. Moreover, studies have reported a direct mutagenic effect of elevated estrogen levels due to the damage caused by oxidative estrogen metabolites, which can lead to oxidative DNA damage and depurination [19]. In addition to increased estrogen synthesis, obesity is also associated with significantly decreased concentrations of the sex hormone-binding globulin (SHBG) [20]. The relative loss of sex steroid-binding capacity again results in elevated serum levels of endocrine-active estrogens. This corresponds to the increased risk of postmenopausal breast cancer and endometrial cancer reported for patients with decreased SHBG serum levels [21, 22].

\section{Current Clinical Data on Obesity and Gynecologic Cancers}

\section{Endometrial cancer}

The strongest correlation between obesity and the risk of developing a malignancy has been reported for endometrial cancer. Widely validated scientific evidence has highlighted the strong, positive, linear correlation between increasing BMI and the incidence of disease as well as the strong, negative, linear correlation with oncological outcomes. Currently, more than half of all newly diagnosed endometrial cancers are associated with obesity and could thus potentially be prevented. The association is strongest in postmenopausal patients with endometrioid adenocarcinoma; a cohort study of 33436 postmenopausal patients reported that obese patients had a more than fourfold increased risk of developing endometrioid adenocarcinoma compared to normal weight patients, while the risk of developing serous, clear-cell or other high-grade cancers was more than twice as high [23]. This corresponds to a $50 \%$ risk increase per $5 \mathrm{BMl}$ units in patients with postmenopausal endometrioid adenocarcinoma [24]. A similar BMIdependent risk constellation has also been reported for patients with premenopausal endometrial cancer, although the data for this is still limited [25]. Cancer-specific mortality is more than twice as high for patients with a BMI between 30 and 34.9, and in patients with a BMI of more than 40 it is more than six times higher [26].

\section{Breast cancer}

There is also solid evidence for an association between obesity and both the incidence and the prognosis of breast cancer, although the respective risk can be stratified according to hormone receptor status and menopausal status. Meta-analyses have found an independent, positive, linear correlation between BMI and postmenopausal, hormone receptor-positive breast cancer, with an $82 \%$ increase in the relative risk of disease. This corresponds to an increase of $10-32 \%$ for the relative risk per $5 \mathrm{~kg} / \mathrm{m}^{2}$ increase in BMI. The slow but continuous increase in weight over the years in this cohort was significantly associated with disease incidence [27]. However, no association has been found between $\mathrm{BMI}$ and postmenopausal hormone receptor-negative breast cancer $[28,29]$.
A higher premenopausal BMI is associated with a decreased relative risk of hormone receptor-positive breast cancer, with every BMI increase of $5 \mathrm{~kg} / \mathrm{m}^{2}$ associated with a $10 \%$ lower incidence. The underlying pathomechanisms are not clear [28]. Another meta-analysis observed a $43 \%$ increased risk for triple-negative breast cancer in populations of premenopausal women but no significant association between obesity and triple-negative cancer in postmenopausal women [30,31].

After adjusting for tumor subtypes and menopausal status, obesity was found to increase the cancer-specific mortality risk and risk of recurrence by about $35-40 \%$ as well as the probability of developing distant metastasis and late recurrence. The available data do not show whether this is due to late diagnosis or more aggressive tumor biology [32].

\section{Epithelial ovarian cancer}

The association between BMI and the risk of disease is only significant for specific histological subtypes and not for all epithelial ovarian cancers. This is according to the current state of research which considers epithelial ovarian cancers as a heterogeneous group of different malignancies. A meta-analysis of 13448 patients found no association between BMI and the incidence of high-grade serous or high-grade endometrioid adenocarcinoma. However, the relative risk of low-grade serous or low-grade endometrioid ovarian cancer was increased by $13 \%$ and $20 \%$, respectively, with a linear positive association with increasing BMI. There was also a weak association with an increase in the relative disease risk for mucinous and clear-cell ovarian cancers of $17 \%$ and $19 \%$, respectively. The strongest association was for serous borderline tumors, which showed a relative risk increase of $20-25 \%$ per $5 \mathrm{~kg} / \mathrm{m}^{2} \mathrm{BMI}$, while the increase was weaker for mucinous borderline tumors at $9-11 \%$ per $5 \mathrm{~kg} / \mathrm{m}^{2}$ BMI. The pathogenetic reasons have not been determined. The effect of BMI on disease risk was found to be stable when compared to BMI data for early adulthood (age 18-20), which points to obesity as an independent risk factor [33]. A retrospective multicenter study with 370 patients found that BMI had no effect on the interval to recurrence, although the study was not sufficiently powered to be able to show differences between the different histotypes [34]. As regards the known stronger effect on hormone receptor-positive breast cancer and endometrial cancer, a subgroup analysis of high-grade serous cancer stratified according to hormone receptor status could provide clinically relevant findings. However, no solid data are currently available.

\section{Vulvar cancer}

Data on obesity for patients with vulvar cancer is limited because of the low incidence of disease. AGO-CaRE-1, currently the largest study with a total of 1618 patients with vulvar cancer, analysed the BMI values of 849 patients with squamous cell carcinomas and found that the rate of local recurrence was twice as high in the cohort of patients with a BMI of more than 30 , although there were no differences in the rates of distant recurrence. Similarly, disease-free overall survival rates were $36 \%$ lower for this cohort. Multivariate analysis showed this to be an independent factor, although there were no differences in $\mathrm{R} 0$ resection rates, chosen therapies and response rates between groups [35]. Further analy- 
sis of the same cohort confirmed a higher rate of local recurrence and shorter progression-free survival rates for obese patients [36].

\section{Cervical cancer}

The currently available data on the association between obesity, disease risk and disease-specific overall survival for cervical cancer is inconsistent. While one meta-analysis of 128233 patients reported a relative increase in disease risk of $8-40 \%$ for obese patients, the possible pathomechanisms remain unclear [37]. The disease-specific mortality rate was higher for obese American women of Caucasian origin, but this could not be verified for obese Afro-American patients. It has been suggested that screening compliance of obese patients may be lower, and lower screening rates can lead to higher cancer-specific mortality rates [38]. According to a number of small case-control studies, part of this effect could be due to the relative increase in the risk for adenocarcinoma but not squamous cell carcinoma $[39,40]$. A retrospective cohort analysis of 944227 American screening patients which included a total of 490 cases with cervical carcinoma highlights the increased risk of disease for obese patients, while no differences were reported with regard to HPV status or histology. The lower rate of diagnosed precancerous cervical lesions in this patient population indicates that screening quality is lower in cohorts with higher BMI [41].

\section{Complication Rates After Surgical Interventions and Obesity}

Operating times are longer and intraoperative blood loss is higher during abdominal oncologic surgery carried out in obese patients, and the rate of short-term postoperative complications is also higher in this cohort. However, obesity had no impact on cancerspecific long-term survival [42]. Although a retrospective cohort study of 514 patients with endometrial cancer showed an increased rate of mild postoperative complications, particularly infection and wound healing complications after laparotomy, a finding that was borne out by a retrospective systematic analysis of 8453 cases, no correlation was found with intraoperative complications or postoperative long-term morbidity [43]. This was also confirmed for patients with ovarian cancer who had cytoreductive surgery [44] and patients with cervical cancer who underwent radical abdominal hysterectomy with pelvic lymph node dissection [45]. The oncologic prognosis of obese patients who had breast cancer surgery was not poorer than that of non-obese patients; however, cosmetic outcomes were significantly poorer, which also reduced postoperative quality of life [46]. Based on the evidence obtained from large, retrospective cohort analyses, a high BMI alone is not a contraindication for radical surgery in gynecologic oncology patients. However, this does not apply to patients with pre-existing obesity-related comorbidities [47]. Given the fact that no indications of an independent correlation between BMI and serious surgical complications have been found to date, carrying out an individual risk-benefit analysis of the perioperative risk for obese patients is essential.

\section{Adjuvant Treatment Strategies}

A non-systematic review of 66 studies found an association between obesity and poorer oncologic outcomes following cytotoxic chemotherapy in patients with ovarian or endometrial cancer. This effect can be ascribed, in the first instance, to the lack of evidence about the pharmacokinetics of cytotoxic therapies in patients with a high BMI or calculated body surface. As regards correlations between dose intensity and response rates, toxicity and survival rates, all of the above suggests that the dose intensity should be maintained, irrespective of the level of obesity [4850]. The guidelines of the American Society of Clinical Oncology argue in favour of fully weight-adapted dosages of cytotoxic therapies and against any reduction of doses, even though the data, particular for morbid obesity, is extremely thin [51]. Even though obese patients have higher toxicity rates, it was not possible to deduce a consequent negative impact on survival from this. Although analysis of the prospective phase-III GAIN trial on adjuvant dose-dense therapy strategies in 3023 breast cancer patients found significantly higher toxicities compared to non-obese patients, the survival rates were the same, which points to suboptimal dose regimens in this patient population [52]. There are currently no comparable data for vulvar or cervical cancer.

It is possible that obese patients with ovarian cancer also benefit less from adjuvant bevacizumab therapy than normal weight patients; however, the data on whether this effect is due to pharmacokinetics or tumor biology is limited and unclear [53]. Comparable observations have also been reported for non-gynecological malignancies [54].

Early clinical data obtained in the context of experimental immunotherapies investigating the therapy response to checkpoint inhibitors (CPI) in patients with non-gynecological malignancies could offer a counterpoint to the findings on cytotoxic therapies. After adjusting for possible cofounders, an Italian retrospective multicenter study with 876 patients, the majority of whom had had malignant melanoma, kidney cell cancer or non-small cell lung cancer, found significantly better response and survival rates for both patients with BMI $\geq 25$ and patients in the cohort with $\mathrm{BMI} \geq 30$. The reason for this was not clear; irrespective of possible dosage bias, tumors encouraged by pathologically increased obese tissue might respond better to CPI therapies. The same effect has also been previously described for smaller independent cohorts, particularly for malignant melanomas $[55,56]$. But because similar data on gynecological malignancies is lacking, there are currently no clinical implications for gynecologic oncology [57].

\section{Outlook and Future Issues}

While BMI is an easy target because it is simple to use and costeffective in clinical practice, the validity of using BMI has repeatedly been criticized, particularly with regard to extreme values and the lack of discriminatory data on muscle percentages or body fat distribution. Clinical alternatives such as waist circumference or waist-to-hip ratio could serve as prognostic factors, as they reflect the oncogenic potential of visceral fatty tissue better. However, the data on this is currently still limited. Although waist- 
- Table 1 Key messages on the clinical relevance and management of obesity and its association with gynecological cancers, based on tumor location. Obesity is defined as a body mass index $(\mathrm{BMI}) \geq 30 \mathrm{~kg} / \mathrm{m}^{2}$.

\begin{tabular}{|c|c|}
\hline Cancer location & Key messages: relevance for clinical practice \\
\hline \multirow[t]{2}{*}{ Endometrium } & pre- und postmenopausal: positive linear correlation with incidence and poorer oncological outcome [23] \\
\hline & postmenopausal endometrioid adenocarcinoma: $50 \%$ increase in relative risk per 5 BMl units [24] \\
\hline \multirow{3}{*}{$\begin{array}{l}\text { Breast } \\
\text { (hormone receptor-positive) }\end{array}$} & postmenopausal: positive linear correlation with incidence and poorer oncological outcome [32] \\
\hline & postmenopausal cancer: $10-32 \%$ increase in relative risk per 5 BMI units [27] \\
\hline & premenopausal cancer: $10 \%$ increase in relative risk per 5 BMl units [28] \\
\hline \multirow{2}{*}{$\begin{array}{l}\text { Breast } \\
\text { (hormone receptor-negative) }\end{array}$} & postmenopausal cancer: relevance for disease risk and risk of cancer-specific mortality is clinically negligible [31] \\
\hline & premenopausal cancer: associated with development of triple-negative cancer [30] \\
\hline Cervix & \multirow[t]{2}{*}{ relevance for disease risk and risk of cancer-specific mortality is clinically negligible ${ }^{1,2}$} \\
\hline Ovary (epithelial) & \\
\hline \multirow[t]{2}{*}{ Vulva } & relevance for disease risk is clinically negligible [35-36] \\
\hline & significantly shorter progression-free and disease-specific survival rates [35-36] \\
\hline \multirow[t]{2}{*}{ Therapy strategies } & $\begin{array}{l}\text { Surgical: obesity without associated morbidity is no contraindication for radical surgical treatment strategies [ } 43- \\
45]\end{array}$ \\
\hline & $\begin{array}{l}\text { Cytotoxic chemotherapy: fully weight-adapted doses associated with better oncological outcomes despite } \\
\text { higher toxicity [ } 48-51]\end{array}$ \\
\hline \multicolumn{2}{|c|}{$\begin{array}{l}1 \text { The relative increase in the risk of developing cervical cancer which has been reported in some studies is probably due to the poorer quality of screening } \\
\text { [41]. }\end{array}$} \\
\hline \multicolumn{2}{|c|}{$\begin{array}{l}2 \text { A relative increase in the risk of developing low-grade, mucinous and clear-cell cancers has been reported, but because of the rarity of these histological } \\
\text { subtypes and the limited effect, the clinical relevance is limited [33]. }\end{array}$} \\
\hline
\end{tabular}

to-hip ratio was identified as an independent prognostic factor in a study of 4062 Chinese patients with breast cancer, there are currently no direct comparisons of the prognostic value of waist-tohip ratio compared to BMI [58].

Because of the negative impact of obesity on the probability of recurrence and on cancer-specific overall survival, it has been suggested that obesely increased fatty tissue could be a potential oncological therapy target in preclinical models [59]. Although widely validated in non-oncological settings, clinical data on the availability of anti-obesity drugs in oncological therapy are lacking. Glucagon-like peptide 1 (GLP-1) receptor antagonists such as liraglutide which inhibits insulin synthesis and decelerates gastric emptying result in a clinical weight loss of $5-10 \%$ of body weight within 20 weeks, with stable long-term effects if treatment is maintained. The effect is comparable to that of other licensed preparations such as the lipase inhibitor orlistat or the serotonin antagonist lorcaserin and is not inferior to bariatric surgery $[60,61]$. A retrospective cohort analysis with a 5 -year follow-up after surgically enforced weight loss reported a reduction in the risk of developing endometrial cancer of up to $40 \%$. There is also broad evidence for a decrease in serum concentrations of sex steroids and insulin [62-64]. A forced reduction of obese fatty tissue by the administration of drugs could therefore be a promising future therapeutic approach.

\section{Conclusion: Relevance for Clinical Practice}

Obesity is an independent risk factor which considerably increases the probability of developing endometrial and postmenopausal breast cancer compared with normal weight patients. The epidemiological associations for cervical cancer, vulvar cancer, epithelial ovarian cancer and premenopausal breast cancer are plausible, but the evidence is less solid and the reported effects less pronounced, especially as HPV screening for the prevention of vulvar and cervical cancer plays a far greater clinical role and no connection has been found for the most common high-grade serous subtypes of epithelial ovarian cancer ( $\vee$ Table 1 ). The data on clinical recommendations for action is thin. Based on current evidence, patients with an increased BMI but no associated comorbidities have no increased risk of serious complications during surgical primary therapy nor do they have higher perioperative mortality rates, which is why radical surgical strategies are not contraindicated. Similarly, dose-reduced cytotoxic chemotherapy regimens for ovarian and endometrial cancer are associated with poorer oncologic outcomes in obese patients, and therefore the recommendation is that obese patients are treated using fully weightadapted dosages despite the potentially higher toxicity. Despite the known negative correlation between BMI, the probability of recurrence and oncologic outcomes, because of the lack of evidence, forced reduction of obese fatty tissue, either through bariatric surgery or drug therapy, must be limited to clinical trials. 


\section{Conflict of Interest}

The authors declare that they have no conflict of interest.

\section{References}

[1] Hales CM, Fryar CD, Carroll MD et al. Trends in obesity and severe obesity prevalence in US youth and adults by sex and age, 2007-2008 to 2015-2016. JAMA 2018; 319: 1723-1725

[2] Berghöfer A, Pischon T, Reinhold T et al. Obesity prevalence from a European perspective: a systematic review. BMC Public Health 2008; 8: 200. doi:10.1186/1471-2458-8-200

[3] Prammer-Waldhör M. Jahrbuch der Gesundheitsstatistik, Wien: Statistik Austria 2019. Accessed September 29, 2020 at: https://www.statistik. at/web_de/services/publikationen/4/index.html?includePage=detailed View\&sectionName $=$ Gesundheit\&publd $=543$

[4] Vucenik I, Stains JP. Obesity and cancer risk: evidence, mechanisms, and recommendations. Ann N Y Acad Sci 2012; 1271: 37-43. doi:10.1111/ j.1749-6632.2012.06750.x

[5] Laviano A, Koverech A, Mari A. Cachexia: clinical features when inflammation drives malnutrition. Proc Nutr Soc 2015; 74: 348-354. doi:10.1017/S0029665115000117

[6] Holzer RG, Park EJ, Li N et al. Saturated fatty acids induce c-Src clustering within membrane subdomains, leading to JNK activation. Cell 2011; 147: 173-184. doi:10.1016/j.cell.2011.08.034

[7] Feuerer M, Herrero L, Cipolletta D et al. Lean, but not obese, fat is enriched for a unique population of regulatory T cells that affect metabolic parameters. Nat Med 2009; 15: 930-939. doi:10.1038/nm.2002

[8] McNelis JC, Olefsky JM. Macrophages, immunity, and metabolic disease. Immunity 2014; 41: 36-48. doi:10.1016/j.immuni.2014.05.010

[9] Weisberg SP, McCann D, Desai M et al. Obesity is associated with macrophage accumulation in adipose tissue. J Clin Invest 2003; 112: 17961808. doi:10.1172/jci19246

[10] Font-Burgada J, Sun B, Karin M. Obesity and Cancer: The Oil that Feeds the Flame. Cell Metab 2016; 23: 48-62. doi:10.1016/j.cmet.2015. 12.015

[11] Solinas G, Vilcu C, Neels JG et al. JNK1 in hematopoietically derived cells contributes to diet-induced inflammation and insulin resistance without affecting obesity. Cell Metab 2007; 6: 386-397. doi:10.1016/j.cmet. 2007.09.011

[12] Aguirre V, Werner ED, Giraud J et al. Phosphorylation of Ser307 in insulin receptor substrate- 1 blocks interactions with the insulin receptor and inhibits insulin action. J Biol Chem 2002; 277: 1531-1537. doi:10.1074/ jbc.M101521200

[13] Nielsen S, Guo Z, Johnson CM et al. Splanchnic lipolysis in human obesity. J Clin Invest 2004; 113: 1582-1588. doi:10.1172/jci21047

[14] Yang Y, Ju D, Zhang $M$ et al. Interleukin-6 stimulates lipolysis in porcine adipocytes. Endocrine 2008; 33: 261-269. doi:10.1007/s12020-0089085-7

[15] McCampbell AS, Broaddus RR, Loose DS et al. Overexpression of the insulin-like growth factor I receptor and activation of the AKT pathway in hyperplastic endometrium. Clin Cancer Res 2006; 12: 6373-6378. doi:10.1158/1078-0432.ccr-06-0912

[16] Dalamaga M, Diakopoulos KN, Mantzoros CS. The role of adiponectin in cancer: a review of current evidence. Endocr Rev 2012; 33: 547-594. doi:10.1210/er.2011-1015

[17] Antuna-Puente B, Feve B, Fellahi S et al. Adipokines: the missing link between insulin resistance and obesity. Diabetes Metab 2008; 34: 2-11. doi:10.1016/j.diabet.2007.09.004
[18] Fasshauer M, Bluher M. Adipokines in health and disease. Trends Pharmacol Sci 2015; 36: 461-470. doi:10.1016/j.tips.2015.04.014

[19] Yager JD. Mechanisms of estrogen carcinogenesis: The role of E2/E1-quinone metabolites suggests new approaches to preventive interventionA review. Steroids 2015; 99: 56-60. doi:10.1016/j.steroids.2014.08.006

[20] Cooper LA, Page ST, Amory JK et al. The association of obesity with sex hormone-binding globulin is stronger than the association with ageingimplications for the interpretation of total testosterone measurements. Clin Endocrinol (Oxf) 2015; 83: 828-833. doi:10.1111/cen.12768

[21] Lukanova A, Lundin E, Micheli A et al. Circulating levels of sex steroid hormones and risk of endometrial cancer in postmenopausal women. Int J Cancer 2004; 108: 425-432. doi:10.1002/ijc.11529

[22] He XY, Liao YD, Yu S et al. Sex hormone binding globulin and risk of breast cancer in postmenopausal women: a meta-analysis of prospective studies. Horm Metab Res 2015; 47: 485-490. doi:10.1055/s-00341395606

[23] McCullough ML, Patel AV, Patel R et al. Body mass and endometrial cancer risk by hormone replacement therapy and cancer subtype. Cancer Epidemiol Biomarkers Prev 2008; 17: 73-79. doi:10.1158/1055-9965. epi-07-2567

[24] Onstad MA, Schmandt RE, Lu KH. Addressing the Role of Obesity in Endometrial Cancer Risk, Prevention, and Treatment. J Clin Oncol 2016; 34: 4225-4230. doi:10.1200/JCO.2016.69.4638

[25] Wise MR, Jordan V, Lagas A et al. Obesity and endometrial hyperplasia and cancer in premenopausal women: A systematic review. Am J Obstet Gynecol 2016; 214: 689.e1-689.e17. doi:10.1016/j.ajog.2016.01.175

[26] Calle EE, Rodriguez C, Walker-Thurmond K et al. Overweight, obesity, and mortality from cancer in a prospectively studied cohort of U.S. adults. N Engl J Med 2003; 348: 1625-1638. doi:10.1056/NEJMoa021423

[27] Emaus M], van Gils CH, Bakker MF et al. Weight change in middle adulthood and breast cancer risk in the EPIC-PANACEA study. Int J Cancer 2014; 135: 2887-2899. doi:10.1002/ijc.28926

[28] Suzuki R, Orsini N, Saji S et al. Body weight and incidence of breast cancer defined by estrogen and progesterone receptor status-a meta-analysis. Int J Cancer 2009; 124: 698-712. doi:10.1002/ijc.23943

[29] Neuhouser ML, Aragaki AK, Prentice RL et al. Overweight, Obesity, and Postmenopausal Invasive Breast Cancer Risk: A Secondary Analysis of the Women's Health Initiative Randomized Clinical Trials. JAMA Oncol 2015; 1: 611-621. doi:10.1001/jamaoncol.2015.1546

[30] Pierobon M, Frankenfeld CL. Obesity as a risk factor for triple-negative breast cancers: a systematic review and meta-analysis. Breast Cancer Res Treat 2013; 137: 307-314. doi:10.1007/s10549-012-2339-3

[31] Schoemaker M], Nichols HB, Wright LB et al. Association of Body Mass Index and Age With Subsequent Breast Cancer Risk in Premenopausal Women. JAMA Oncol 2018; 4: e181771. doi:10.1001/jamaoncol.2018. 1771

[32] Jiralerspong S, Goodwin PJ. Obesity and Breast Cancer Prognosis: Evidence, Challenges, and Opportunities. J Clin Oncol 2016; 34: 42034216. doi:10.1200/jco.2016.68.4480

[33] Catherine MO, Christina MN, David CW et al. Obesity and risk of ovarian cancer subtypes: evidence from the Ovarian Cancer Association Consortium. Endocr Relat Cancer 2013; 20: 251-262. doi:10.1530/ERC-120395

[34] Hew KE, Bakhru A, Harrison E et al. The Effect of Obesity on the Time to Recurrence in Ovarian Cancer: A Retrospective Study. Clinical Ovarian and Other Gynecologic Cancer 2013; 6: 31-35. doi:10.1016/j. cogc.2014.02.002

[35] Klapdor R, Hillemanns P, Woelber LL et al. The influence of obesity on tumor recurrence in vulvar cancer patients. J Clin Oncol 2019; 37: e17130. doi:10.1200/JCO.2019.37.15_suppl.e17130 
[36] Klapdor R, Hillemanns P, Wölber L et al. Association between obesity and vulvar cancer recurrence: an analysis of the AGO-CaRE-1 study. Int J Gynecol Cancer 2020; 30: 920-926. doi:10.1136/ijgc-2019-001187

[37] Poorolajal J, Jenabi E. The association between BMI and cervical cancer risk: a meta-analysis. Eur J Cancer Prev 2016; 25: 232-238. doi:10.1097/cej.0000000000000164

[38] Maruthur NM, Bolen SD, Brancati FL et al. The association of obesity and cervical cancer screening: a systematic review and meta-analysis. Obesity (Silver Spring) 2009; 17: 375-381. doi:10.1038/oby.2008.480

[39] Lacey JV jr., Swanson CA, Brinton LA et al. Obesity as a potential risk factor for adenocarcinomas and squamous cell carcinomas of the uterine cervix. Cancer 2003; 98: 814-821. doi:10.1002/cncr.11567

[40] Modesitt SC, van Nagell JR jr. The impact of obesity on the incidence and treatment of gynecologic cancers: a review. Obstet Gynecol Surv 2005; 60: 683-692. doi:10.1097/01.ogx.0000180866.62409.01

[41] Clarke MA, Fetterman B, Cheung LC et al. Epidemiologic Evidence That Excess Body Weight Increases Risk of Cervical Cancer by Decreased Detection of Precancer. J Clin Oncol 2018; 36: 1184-1191. doi:10.1200/ JCO.2017.75.3442

[42] Ri M, Aikou S, Seto Y. Obesity as a surgical risk factor. Ann Gastroenterol Surg 2017; 2: 13-21. doi:10.1002/ags3.12049

[43] Bouwman F, Smits A, Lopes A et al. The impact of BMI on surgical complications and outcomes in endometrial cancer surgery-an institutional study and systematic review of the literature. Gynecol Oncol 2015; 139 : 369-376. doi:10.1016/j.ygyno.2015.09.020

[44] Smits A, Lopes A, Das N et al. Surgical morbidity and clinical outcomes in ovarian cancer - the role of obesity. BJOG 2016; 123: 300-308. doi:10.1111/1471-0528.13585

[45] Frumovitz M, Sun CC, Jhingran A et al. Radical hysterectomy in obese and morbidly obese women with cervical cancer. Obstet Gynecol 2008; 112 : 899-905. doi:10.1097/AOG.0b013e3181863280

[46] Lee K, Kruper L, Dieli-Conwright CM et al. The Impact of Obesity on Breast Cancer Diagnosis and Treatment. Curr Oncol Rep 2019; 21: 41. doi:10.1007/s11912-019-0787-1

[47] Benjamin ER, Dilektasli E, Haltmeier T et al. The effects of body mass index on complications and mortality after emergency abdominal operations: The obesity paradox. Am J Surg 2017; 214: 899-903. doi:10.1016/ j.amjsurg.2017.01.023

[48] Horowitz NS, Wright AA. Impact of obesity on chemotherapy management and outcomes in women with gynecologic malignancies. Gynecol Oncol 2015; 138: 201-206. doi:10.1016/j.ygyno.2015.04.002

[49] Hanna RK, Poniewierski MS, Laskey RA et al. Predictors of reduced relative dose intensity and its relationship to mortality in women receiving multi-agent chemotherapy for epithelial ovarian cancer. Gynecol Oncol 2013; 129: 74-80. doi:10.1016/j.ygyno.2012.12.017

[50] Au-Yeung G, Webb PM, DeFazio A et al. Impact of obesity on chemotherapy dosing for women with advanced stage serous ovarian cancer in the Australian Ovarian Cancer Study (AOCS). Gynecol Oncol 2014; 133: 1622. doi:10.1016/j.ygyno.2014.01.030
[51] Griggs J], Mangu PB, Anderson H et al. Appropriate chemotherapy dosing for obese adult patients with cancer: American Society of Clinical Oncology clinical practice guideline. J Clin Oncol 2012; 30: 1553-1561. doi:10.1200/jco.2011.39.9436

[52] Furlanetto ], Eiermann W, Marmé F et al. Higher rate of severe toxicities in obese patients receiving dose-dense (dd) chemotherapy according to unadjusted body surface area: results of the prospectively randomized GAIN study. Ann Oncol 2016; 27: 2053-2059. doi:10.1093/annonc/ mdw315

[53] Slaughter KN, Thai T, Penaroza S et al. Measurements of adiposity as clinical biomarkers for first-line bevacizumab-based chemotherapy in epithelial ovarian cancer. Gynecol Oncol 2014; 133: 11-15. doi:10.1016/j.ygyno.2014.01.031

[54] Artaç M, Korkmaz L, Coşkun H et al. Bevacuzimab May Be Less Effective in Obese Metastatic Colorectal Cancer Patients. J Gastrointest Cancer 2019; 50: 214-220. doi:10.1007/s12029-017-0047-2

[55] Richtig G, Hoeller C, Wolf $M$ et al. Body mass index may predict the response to ipilimumab in metastatic melanoma: An observational multicentre study. PLoS One 2018; 13: e0204729. doi:10.1371/journal. pone.0204729

[56] McQuade JL, Daniel CR, Hess KR et al. Association of body-mass index and outcomes in patients with metastatic melanoma treated with targeted therapy, immunotherapy, or chemotherapy: a retrospective, multicohort analysis. Lancet Oncol 2018; 19: 310-322. doi:10.1016/S14702045(18)30078-0

[57] Cortellini A, Bersanelli M, Buti S et al. A multicenter study of body mass index in cancer patients treated with anti-PD-1/PD-L1 immune checkpoint inhibitors: when overweight becomes favorable. J Immunother Cancer 2019; 7: 57. doi:10.1186/s40425-019-0527-y

[58] Zhang M, Cai H, Bao P et al. Body mass index, waist-to-hip ratio and late outcomes: a report from the Shanghai Breast Cancer Survival Study. Sci Rep 2017; 7: 6996. doi:10.1038/s41598-017-07320-7

[59] Sirin O, Kolonin MG. Treatment of obesity as a potential complementary approach to cancer therapy. Drug Discov Today 2013; 18: 567-573. doi:10.1016/j.drudis.2012.05.008

[60] Mehta A, Marso SP, Neeland IJ. Liraglutide for weight management: a critical review of the evidence. Obes Sci Pract 2017; 3: 3-14. doi:10.1002/osp4.84

[61] Schauer DP, Feigelson HS, Koebnick C et al. Association Between Weight Loss and the Risk of Cancer after Bariatric Surgery. Obesity (Silver Spring) 2017; 25 (Suppl. 2): S52-S57. doi:10.1002/oby.22002

[62] Campbell KL, Foster-Schubert KE, Alfano CM et al. Reduced-calorie dietary weight loss, exercise, and sex hormones in postmenopausal women: randomized controlled trial. J Clin Oncol 2012; 30: 2314-2326. doi:10.1200/jco.2011.37.9792

[63] Monninkhof EM, Velthuis M], Peeters PH et al. Effect of exercise on postmenopausal sex hormone levels and role of body fat: a randomized controlled trial. J Clin Oncol 2009; 27: 4492-4499. doi:10.1200/jco.2008. 19.7459

[64] McTiernan A, Tworoger SS, Ulrich CM et al. Effect of exercise on serum estrogens in postmenopausal women: a 12-month randomized clinical trial. Cancer Res 2004; 64: 2923-2928. doi:10.1158/0008-5472.can03-3393 